\title{
Penjernihan Air Bersih dengan Filter Alami dan Aerasi di Teluk Bakung, Sungai Ambawang, Kubu Raya
}

\author{
Mochamad Hilmy *, Herry Prabowo \\ Program Studi Arsitektur Bangunan Gedung \\ Politeknik Negeri Pontianak \\ email: prabowoherry@yahoo.com
}

\begin{abstract}
Fresh water is a vital requirement in human daily life. Teluk Bakung Village relies on fresh water supplies from the Ambawang River and wells made by the community. The condition of well water in Teluk Bakung Village tends to be the color of ground water which is influenced by the roots of trees, blackish brown and high iron content. The purpose of this Community Service activity is to carry out water filtration on gambut soil to improve the condition of fresh water sources at Al-Muhajirin Mosque in Mu'allaf village, Teluk Bakung Village, Sungai Ambawang District, Kubu Raya Regency, Kalimantan Barat as meeting the mosque's needs and the society. The method of applying IPTEKS is by transferring IPTEKS by improving the physical condition of the Al-Muhajirin Mosque building, the application of clean water filtration as well as training the local staffs for operations and maintenance as well as the plumbing network. It is expected that the addition of aeration system groundwater that has iron content will make it clearer than just filtration which has been carried out at that location.
\end{abstract}

Keywords: Clean water, peatlands, natural filtration, aeration

\begin{abstract}
Abstrak
Air bersih merupakan kebutuhan yang sangat vital dalam kehidupan manusia sehari hari. Desa Teluk Bakung mengandalkan pasokan air bersih dari Sungai Ambawang dan sumur yang dibuat oleh masyarakat. Kondisi air sumur di Desa Teluk Bakung cenderung berwarna khas air tanah yang terpengaruhi oleh akar pepohonan, coklat agak kehitaman serta berkadar besi tinggi. Tujuan dari kegiatan Pengabdian Pada Masyarakat ini adalah melakukan Melakukan filtrasi air di tanah gambut untuk perbaikan kondisi sumber air bersih di Masjid Al-Muhajirin di kampung mu'allaf Desa Teluk Bakung, Kecamatan Sungai Ambawang, Kabupaten Kubu Raya, Kalimantan Barat sebagai pemenuhan kebutuhan masjid dan lingkungan masyarakat. Metode penerapan IPTEKS dengan melakukan transfer IPTEKS dengan cara memperbaiki kondisi fisik bangunan Masjid Al-Muhajirin, aplikasi filtrasi air bersih serta pelatihan kepada tenaga lokal untuk operasional dan perawatan serta jaringan plumbingnya. Penambahan sistem aerasi diharapkan air tanah yang memiliki kadar besi akan menjadikan lebih jernih dibandingkan hanya melakukan filtrasi saja yang selama ini dilakukan di lokasi tersebut.
\end{abstract}

Kata Kunci : Air bersih, lahan gambut, filtrasi alami, aerasi

\section{PENDAHULUAN}

Desa Teluk Bakung merupakan salah satu desa hasil pemekaran wilayah di Kecamatan Sungai Ambawang, Kabupaten Kubu Raya, Kalimantan Barat. Desa Teluk Bakung merupakan salah satu desa yang berada di Kecamatan Sungai Ambawang, Kabupaten Kubu Raya. Dusun Lintang Batang, adalah salah satu dusun di dalamnya. Desa ini memiliki luas wilayah daratan kurang lebih $216,88 \mathrm{~km} 2$ [1]. Jumlah penduduk Desa Teluk Bakung Kecamatan Sungai Ambawang Kabupaten Kubu Raya 918 KK, dari jumlah Kepala Keluarga tersebut terdapat 54 KK penduduk muslim muallaf, atau sekitar 5\% dari jumlah penduduk keseluruhan desa ini [2]. Kegiatan keagamaan dan kegiatan 
lainnya bagi para muslim muallaf terpusat di Masjid Almuhajirin.

Air bersih merupakan kebutuhan yang sangat vital dalam kehidupan manusia sehari hari. Desa Teluk Bakung mengandalkan pasokan air bersih dari Sungai Ambawang dan sumur yang dibuat oleh masyarakat. Pada khususnya di Masjid Al Muhajirin, selain untuk kebutuhan masyarakat sekitar, baik untuk berwudlu maupun untuk kehidupan sehari hari, juga dimanfaatkan oleh para musafir yang singgah ketika melakukan perjalanan luar kota. Kondisi air yang tidak jernih dan sedikit berbau memberikan kecanggungan bagi masyarakat luar daerah.

Kondisi air sumur di Desa Teluk Bakung cenderung berwarna khas air tanah yang terpengaruhi oleh akar pepohonan, coklat agak kehitaman dan berkadar besi tinggi $(\mathrm{Fe})$. Standart baku mutu yang ditetapkan oleh pemerintah untuk keberadaan kadar besi $(\mathrm{Fe})$ di dalam air adalah maksimal $0,3 \mathrm{mg} / \mathrm{L}$ [3]. Filtrasi adalah proses pemisahan solid-liquid dengan cara

melewatkan liquid melalui media berpori atau bahan - bahan untuk menyisihkan atau menghilangkan sebanyak - banyaknya butiran-butiran halus zat padat tersuspensi dari liquida [4]. Penurunan kadar besi $(\mathrm{Fe})$ dengan sistem Filtrasi dengan media kerikil, arang tempurung kelapa dan pasir silika dapat menurunkan kadar besi (Fe) hingga mencapai per-sentase sebesar 89,2\% [5]. Efisiensi penyisihan kadar besi $(\mathrm{Fe})$ yang terdapat di dalam air, didapatkan untuk jenis tray aerator memiliki efisiensi penyisihan kadar besi (Fe) lebih besar dibandingkan dengan diffuser aerator [3].

Penggunaan media filter pasir halus yang diletakan pada tabung filter pertama sebagai proses filtrasi awal bertujuan untuk menyaring padatan - padatan berupa sedimen - sedimen tanah yang tersuspensi di dalam air gambut. Penggunaan jenis aliran dari atas kebawah (downflow) dengan memanfatatkan gaya gravitasi merupakan salah satu faktor yang membuat waktu kontak air gambut dengan media filter pasir halus menjadi efektif sehingga padatan - padatan yang terdapat di air gambut dapat disaring didalam media filter pasir halus. Pengolahan air gambut dengan menggunakan sistem filtrasi telah mampu meningkatkan kualitas air gambut dengan parameter yaitu, derajat keasaman $(\mathrm{pH})$ dari 3,3 menjadi 7,6, Zat Organik dari $79 \mathrm{mg} / 1$ menjadi $11,4 \mathrm{mg} / \mathrm{l}$, kekeruhan dari 88,8 NTU menjadi 4 NTU, dan besi (Fe) dari $6,324 \mathrm{mg} / \mathrm{l}$ menjadi $1,728 \mathrm{mg} / \mathrm{l}$. Efektifitas penurunan nilai dari masing-masing parameter kualitas air gambut yaitu, kekeruhan sebesar 95,45\%, $\mathrm{Ph}$ sebesar $57,89 \%$. Besi $(\mathrm{Fe})$ sebesar $72,78 \%$ dan zat organik sebesar $85,57 \%$ [6].

Tujuan dari kegiatan Pengabdian Pada Masyarakat ini adalah melakukan Melakukan filtrasi air di tanah gambut untuk perbaikan kondisi sumber air bersih di Masjid Al-Muhajirin di kampung mu'allaf Desa Teluk Bakung, Kecamatan Sungai Ambawang, Kabupaten Kubu Raya, Kalimantan Barat sebagai pemenuhan kebutuhan masjid dan lingkungan masyarakat. Filtrasi yang dilakukan dengan metode yang sederhana, murah dan tidak membahayakan lingkungan. Filtrasi dengan menggunakan sistem alami serta penambahan aerasi diharap mampu membantuk masyarakat untuk meminimalisir masalah yang ada.

\section{METODE PENGABDIAN}

Metode yang diterapkan adalah dengan 2 cara alternatif. Metode yang pertama adalah filtrasi yang digunakan adalah dengan pemanfaatan material alami seperti pasir kerang, ijuk, batu split dan arang aktif. Metode yang kedua adalah dilakukan penambahan aerasi dan pengendapan sebelum air dilakukan filterasi. Hal ini dianggap sebagai tahapan yang penting untuk memberikan perbedaan yang signifikan dibandingkan dengan metode pertama. Oksidasi yang terjadi pada proses aerasi inilah untuk 
memisahkan kadar besi dari air baku. System aerasi yang digunakan adalah tray aerator. System ini terbukti paling efektif dan efisien, sehingga mudah diaplikasikan di lokasi pelaksanaan pengabdian masyarakat yang terpilih.

Sistem filtrasi dengan penambahan system aerasi ini didukung dengan struktur vertikal berkonstruksi kayu. Kayu yang dimanfaatkan adalah kayu kombinasi antara kayu belian dan kayu rengas. Kayu belian diterpakan untuk system pondasi dan tiang utama serta keep dan gelegar (balok) serta papan. Kayu rengas diaplikasikan untuk bagian-bagian yang memudahkan dilakukan penggantian jika suatu saat nanti terjadi kerusakan. Pengerjaan konstruksi dengan kayu diharapkan terselesaikan dengan lebih cepat, serta terbiasanya masyarakat sekitar dengan teknologi pengerjaan yang ada, sehingga meminimalisir terjadinya kesalahan atau kurangnya kualitas pembangunan. Penggunaan pondasi tiang tongkat kayu belian dipilih karena lebih praktis di musim penghujan, serta lebih praktis dikerjakan di lahan gambut. Antar titik-titik pondasi dihubungkan dengan balok kayu horizontal yang berfungsi sebagai pengikat antar pondasi sekaligus berfungsi sebagai tumpuan balok lantai. Balok ini sering disebut dengan balok keep yang dipasang pada ketinggian yang disesuaikan dengan ketinggian muka air sungai tertinggi [7].

Guna meminimalisasi energi yang digunakan, sistem yang dipilih ini menggunakan tenaga listrik hanya untuk menaikkan air dari sumur bor ke keranjang aerator. Setelah mengalami aerasi, air akan dialirkan secara perlahan sambil dilakukan pengendapan. Selebihnya filtrasi berjalan dengan mengandalkan gravitasi, air akan mengalir secara perlahan agar dapat tersaring sempurna. Tahapan pengendapan yang dilakukan diharapkan akan menambah masa perawatan media filtrasi berupa batu split, pasir kerang, arang dan ijuk.

\section{HASIL DAN PEMBAHASAN}

Pengolahan air sistem filtrasi metode pertama yaitu dengan media alami saja, yaitu pasir kerang dan ijuk telah dilakukan dan hasilnya masih belum memuaskan secara visual dan aromatik. Kekeruhan telah jauh berkurang, namun warnanya masih kekuningan dan masih menimbulkan bau khas air gambut, terutama jika sedang terjadi hujan lebat. Secara kasat mata kandungan besi masih cukup tinggi.
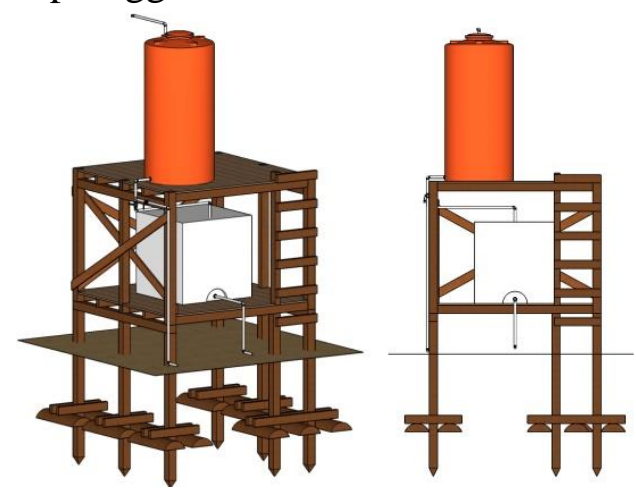

Gambar 1. Filtrasi dengan media alami

Penerapan metode kedua mendapatkan hasil tersedianya filtrasi air bersih dengan penambahan aerasi dan system pengendapan. Sistem pengendapan dengan pengaliran lambat diharapkan memaksimalkan sistem yang bekerja. Air yang selama ini berwarna coklat kehitaman serta berbau, dapat dijernihkan dan layak dipergunakan untuk memenuhi kebutuhan masyarakat. Sistem aerasi terbukti mumpuni untuk menurunkan kadar besi yang ada di dalam air. Kandungan besi yang ada diminimalisir dengan sistem aerasi yang dilakukan. Besi yang terbawa oleh angin berusaha ditangkap dengan paranet sebagai perangkapnya, sehingga tidak beterbangan mengenai lingkungan di sekitarnya. Penggunaan paranet mampu menangkap serbuk besi yang berterbangan namun tetap dapat dilalui oleh aliran udara agar proses oksidasi tetap terjadi. 


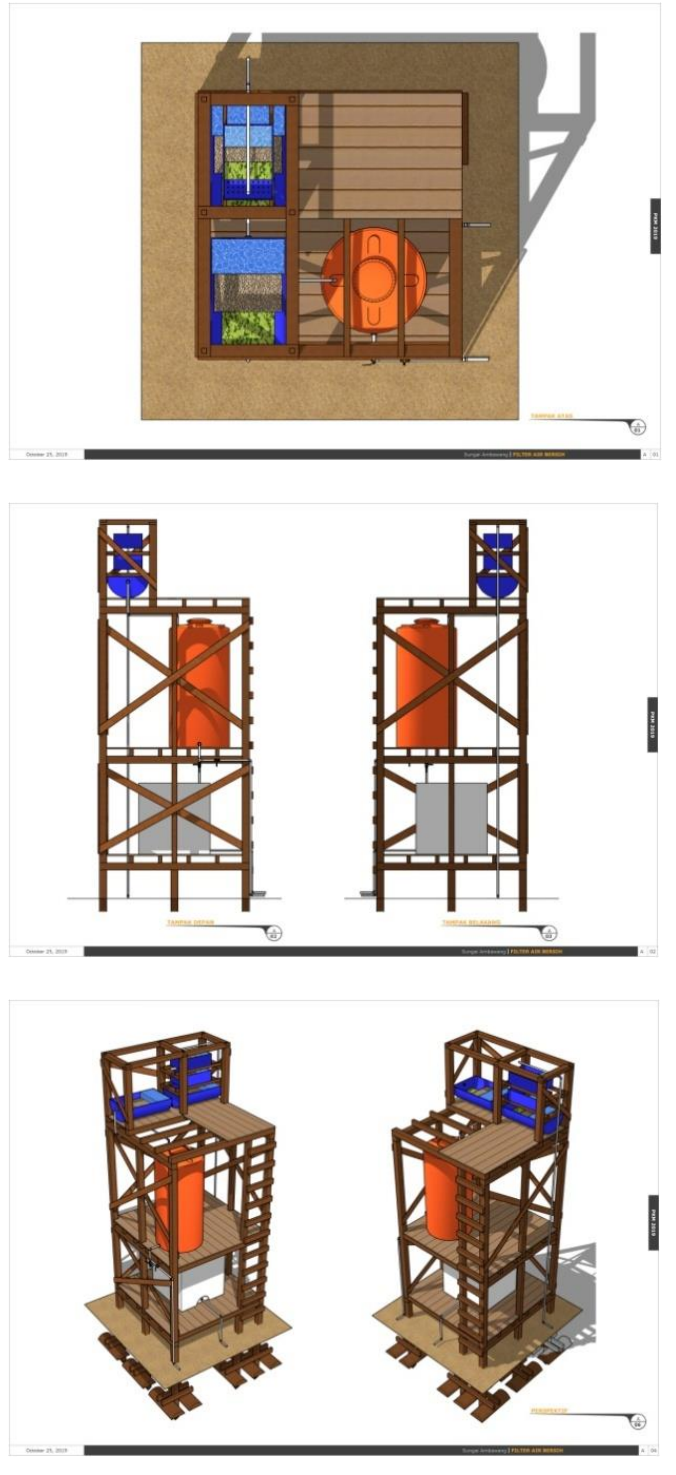

Gambar 2. Filtrasi dengan aerasi dan pengendapan

\section{SIMPULAN}

Filtrasi yang dilakukan lebih optimal setelah dilakukan dengan mempertinggi media filter berupa batu split, pasir, arang dan ijuk. Penambahan system aerasi dengan tray aerator terbukti cukup optimal untuk mengurangi kandungan besi di dalam air baku yang ada di tanah gambut. Penampungan hasil dari sistem aerasi secara horizontal menjadi pengaliran lambat dan terjadi pengendapan.

\section{UCAPAN TERIMAKASIH}

Ungkapan terima kasih ditujukan kepada Politeknik Negeri Pontianak selaku penyandang dana utama, Okto Ivansyah, S.Si., M.T. selaku ahli geofisika sekaligus sebagai praktisi dalam pengadaan air bersih. Ucapan terima kasih sebesar besarnya juga disampaikan kepada pengurus Masjid Almuhajirin dan masyarakat di sekitar lokasi kegiatan serta seluruh pihak yang terlibat secara teknis.

\section{DAFTAR PUSTAKA}

[1] T. Juliansyah, "Tribun Kubu Raya," 28 Maret 2019. [Online]. Available: http://pontianak.tribunnews.com/201 9/03/28/desa-teluk-bakung-milikitiga-polindes.

[2] S. R. Idris, "Manajemen Lembaga Pembinaan Mu'allaf Desa Teluk Bakung Sungai Ambawang Kubu Raya," in Prosiding Seminar Nasional Manajemen Dakwah IAIN Pontianak, Pontianak, 2017.

[3] A. L. d. A. Purnomo, "Analisis penurunan kadar besi dengan menggunakan tray aerator dan diffuser aerator," Jurnal Teknik ITS Vol. 4, No. 1, (2015) ISSN: 23373539, pp. 125-127, 2015.

[4] U. B. J. d. I. Nurhayati, "Pengaruh Penggunaan Media Filtrasi Terhadap Kualitas Air," Jurnal Teknik Waktu Volume 12 Nomor 02 - Juli 2014 ISSN : 1412-1867, pp. 34-38, 2014.

[5] M. S. Rasman, "Penurunan Kadar Besi (Fe) Dengan Sistem Aerasi dan Filtrasi Pada Air Sumur Gali (Eksperimen)," Higinie Vlolume 2, No. 3, September - Desember 2016, pp. 159-167, 2016.

[6] Y. F. d. A. R. Anugrah Rais, "Perikanan, Rrancang Bangun Alat Pengolahan Air Gambut Dengan Sistem Filtrasi Untuk Budidaya," Jurnal Teknologi Lingkungan Lahan Basah Vol.5, No. 1. issn: 2622-2884, 
pp. $\quad 1-10 \quad$ DOI:

http://dx.doi.org/10.26418/jtllb.v5i1.

18354, 2017.

[7] Z. Z. R. I. Lestari, "Mengenal Arsitektur Lokal: Konstruksi Rumah Kayu Tepian Sungai Kapuas, Pontianak," Langkau Betang, Vol. 3, No. 2, 2016, pp. 1-11, 2016. 